\title{
Spatial Variation of Soil Texture in the World Heritage Site of Indian Sundarbans
}

\author{
Arpita Saha ${ }^{1 *}$, Arpan Mitra ${ }^{2}$, Nabonita Pal ${ }^{1}$, Sufia Zaman ${ }^{1}$ and Abhijit Mitra ${ }^{3}$ \\ ${ }^{1}$ Department of Oceanography, Techno India University, West Bengal, Kolkata, India \\ ${ }^{2}$ A. Mitra and Company, Kolkata, India \\ ${ }^{3}$ Department of Marine Science, University of Calcutta, Kolkata, India \\ *Corresponding Author: Arpita Saha, Department of Oceanography, Techno India University, West Bengal, Kolkata, India
}

Received: July 11, 2019; Published: July 16, 2019

DOI: 10.31080/ASMI.2019.02.0311

\section{Abstract}

A study was conducted on soil texture in 24 stations distributed in the western, eastern and central Indian Sundarbans during 2018. The region is dominated by mangroves although the western sector is more prone to anthropogenic disturbances. It is observed that in all the stations sand exhibited maximum percentage (32\% - 55\%), followed by silt (25\% - 32\%) and clay (11\% - 25\%). Keywords: Soil Texture; Indian Sundarbans; Mangroves

\section{Introduction}

The mangrove dominated Indian Sundarbans possesses several types of habitats like estuaries, mudflats, swamps, tidal creeks, inlets etc. [1]. The temperature is not extreme in summer and winter seasons due to its proximity to the Bay of Bengal in the southern part of the deltaic complex. Average annual maximum temperature is around $27^{\circ} \mathrm{C}$. The premonsoon season extends from the mid of March to June, and the postmonsoon seasons lasts from November to February. The monsoon usually sets in July and lasts up to the end of October. Rough weather with frequent cyclonic depressions occurs during mid-March to mid-September. Average annual rainfall is $1700 \mathrm{~mm}$. Average relative humidity is about $85 \%$ which indicates high moisture load in the air. This unique ecosystem is the resident place of Royal Bengal Tiger (Panthera tigris tigris). The deltaic complex sustains more than 100 islands, out of which about $50 \%$ are inhabited. The major threats on the ecosystem are high tides and waves due to which erosion occurs. The average tidal amplitude is around $3.0 \mathrm{~m}$. We conducted survey at 24 stations in the Indian Sundarban region in February, 2018. Station selection was primarily based considering the blocks in Indian Sundarban. The present study has great implication as the agricultural productivity, pisciculture and construction of ecotourism units in this deltaic complex stand on the foundation of soil texture.

\section{Materials and Methods}

Sampling Stations

The major parts of Sundarbans lies in Bangladesh (62\%) and in India the area is less (38\%). This is the world's largest coastal wetland. Enormous load of sediments carried by the rivers contribute to its expansion and dynamics. The Indian Sundarban (between $21^{\circ} 13^{\prime} \mathrm{N}$ and $22^{\circ} 40^{\prime} \mathrm{N}$ latitude and $88^{\circ} 03^{\prime} \mathrm{E}$ and $89^{\circ} 07^{\prime} \mathrm{E}$ longitude) is bordered by Bangladesh in the east, the Hooghly River (a continuation of the River Ganga) in the west, the Dampier and Hodges line in the north, and the Bay of Bengal in the south. 24 stations were selected in the Indian Sundarban region in February, 2018 to carry out this programme (Figure 1).

\section{Experimental analysis}

Figure 1 represents our study site in which sampling plots of 2 $\mathrm{m} \times 2 \mathrm{~m}$ were considered for each station. Care was taken to collect the samples from uniform distance from the adjacent estuary. Under such conditions, variations of physico-chemical parameters are minimum [2-4]. Because of regular tidal flushing sediment input and riverine inputs of silt and clay, a significant spatial difference of soil texture is noted in Indian Sundarbans. Study of soil texture is important as the agricultural productivity in Indian Sundarbans is dependent on water holding capacity of the soil, which in turn 
is regulated by the texture of Sundarban soil. The vast mangrove vegetation in Indian Sundarbans produces litter and detritus which finally get transformed into silt and clay. Sand is brought in the system through tidal actions from the Bay of Bengal.

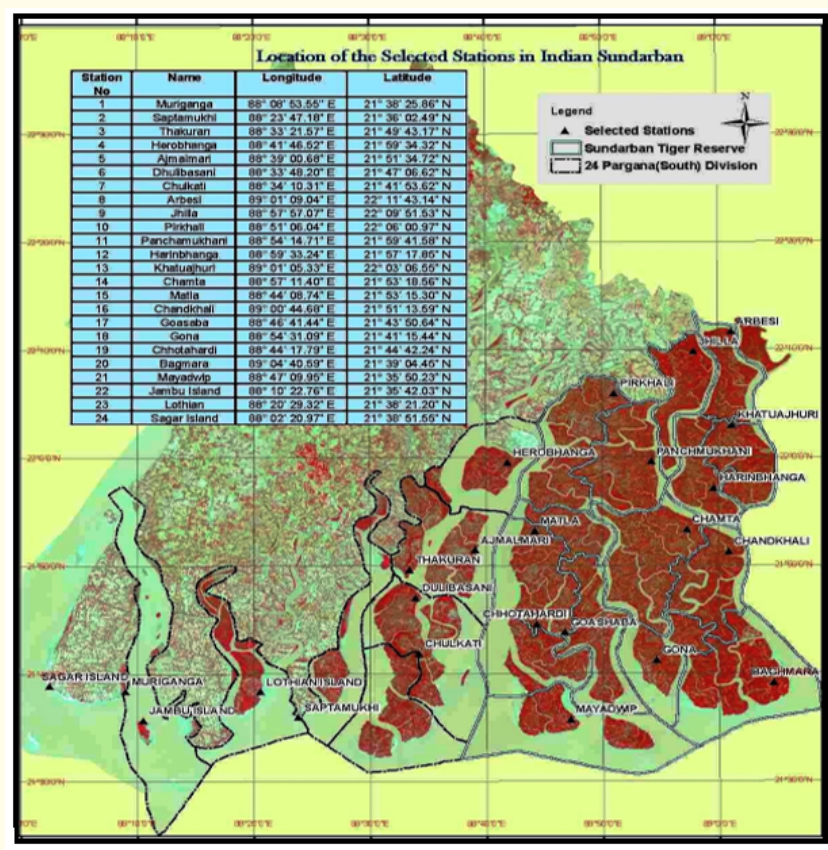

Figure 1: Selected stations in Indian Sundarbans with their respective coordinates.

\section{Texture analysis}

Mechanical analysis for texture was carried out using the International Pipette method. In this method, the soil sample was treated to remove the organic matter with hydrogen peroxide. Soluble matter was removed by washing and filtering with Pasteur- Chamber land suction filters. The sample was dried and weighed, and this weight was the basis of calculation of percentages of material in each size class. The results were finally used in textural classification.

\section{Results and Discussion}

In the soil of Indian Sundarbans, the percentage of sand is higher, followed by that of silt and clay. So the soil is mainly sandyloam in nature. Such soils have visible particles of sand mixed into the soil. When sandy loams soils are squeezed, they break apart easily due to abundance of sand. Such soils have low water hol- ding capacity, high permeability and low nutrient storage capacity. The percentage of sand in the soil is maximum in the central sector followed by the western and eastern sectors (Figure 2).

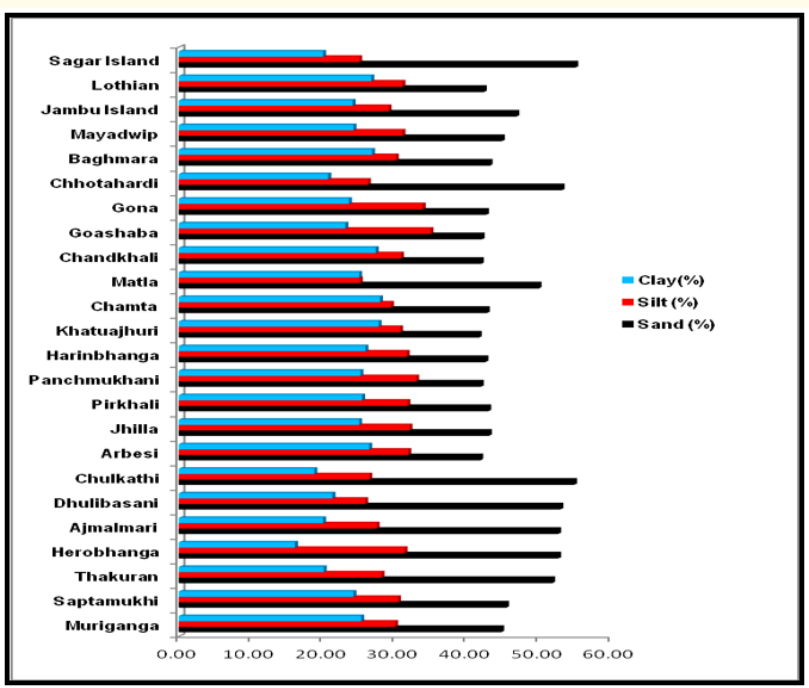

Figure 2: Spatial variation of sand, silt and clay percentages in Indian Sundarbans.

Soils in Indian Sundarbans are mainly loamy in nature. The soil texture varies from sandy- loam to clay- loam. Study of soil texture has several implications. It helps to determine how much water will be able to percolate vertically through the soil layers. In the present study it is found that the soils in the central sector of Indian Sundarbans (station 3 , station 4 , station 5 , station 6 , station 7 , station 15 are station 19) are dominated by sand (average 52.53\%), which is an indication of decreased transference of silt and clay through fresh water. The siltation of Bidyadhari since the late 15th century may be the best possible reason for this textural variation [1, 5-10]. Silt and clay are contributed in the soil of the present study area through riverine discharges via Hooghly and Muriganga in the western sector and through several creeks connected with Harinbhanga River in the eastern most boarder of Indian Sundarbans.

\section{Conclusion}

The present study has great significance in the agricultural sector as the study area is a mono cropping zone due to high salinity. Under normal irrigation practices more water will percolate to the root system of the plant growing in sandy soil. This lead us to conclude that clay soils are at a greater risk than course textured sandy 
soils as considerable sodium get accumulated resulting in stunted growth of the vegetation.

\section{Bibliography}

1. AB Chaudhuri and A Choudhury. "Mangroves of the Sundarbans". The World Conservation Union, Dhaka, (1994).

2. ARC Ovalle., et al. "Factors affecting the hydrochemistry of a mangrove tidal creek, Sepetiba Bay, Brazil”. Estuarine, Coastal and Shelf Science 31 (1990): 639-650.

3. LD Lacerda., et al. "The biogeochemistry and trace metals distribution of mangrove rhizospheres". Biotropica 25 (1993): 251-256.

4. KF Tanizaki. "Biogeoquímica de metais pesados na rizosfera de plantas de um manguezal do Rio de Janeiro". M.Sc. Thesis, Departamento de Geoquímica, Universidade Federal Fluminense, Niterói (1994): 67.

5. Mitra. "In: Sensitivity of Mangrove ecosystem to changing Climate". Springer (2013).

6. Mitra and S Zaman. "Carbon Sequestration by Coastal Floral Community". The Energy and Resources Institute (TERI), TERI Press, India, (2014).

7. A Mitra and S Zaman. "Blue carbon reservoir of the blue planet" (2015).

8. A Mitra and S Zaman, "Basics of Marine and Estuarine Ecology”. Springer (2016).

9. S Trivedi., et al. "Inter-annual variation of salinity in Indian Sundarbans". Indian Journal of Geo-Marine Sciences 45 (2016): 410-415.

10. A Mitra., et al. "In: Environmental coastguards". Published by CSIR-National Institute of Science Communication and Information Resources (CSIR-NISCAIR), (2017).

Volume 2 Issue 8 August 2019

(C) All rights are reserved by Arpita Saha., et al. 